\title{
The Development of Synaptic Function and Integration in the Central Auditory System
}

\author{
Dan H. Sanes \\ Center for Neural Science and Department of Biology, New York University, New York, New York 10003
}

The development of inhibitory synaptic transmission is difficult to assess because the afferents usually arise from intrinsic neurons that are difficult to stimulate independently. The postnatal maturation of excitatory and inhibitory synaptic function was compared in the gerbil lateral superior olive (LSO), where it is possible to stimulate physically discrete afferent projections. Intracellular recordings obtained in a brain slice preparation revealed that transmission was prominent at birth. The EPSPs and IPSPs were up to 2 orders of magnitude longer than in more mature animals. Brief trains of electrical stimulus pulses led to a temporal summation of postsynaptic potentials (PSPs) in 1-14 d animals resulting in prolonged depolarizations or hyperpolarizations. In neonates, the depolarization could exceed 1 sec following a 70 msec stimulus train. The IPSPs in neonates were often of sufficient amplitude to evoke a rebound depolarization or action potential. The number of converging afferents was estimated from the quantized increases in PSP size. There was a significant decrease with age, suggesting that both inhibitory and excitatory afferents were eliminated during the first 3 postnatal weeks. The integration of action potentials with IPSPs was examined with conjoint stimuli to the two afferent pathways, and demonstrated that the effective IPSP duration decreased $\approx 20$-fold during the first 3 postnatal weeks.

The magnitudes and durations of electrical stimulusevoked PSPs suggest that spontaneous discharge of afferents to the LSO could have a substantial impact on their development, even prior to the response to airborne sound at 12 d. Furthermore, the synaptic responses obtained at 12-14 d postnatal indicated that both amplitude and temporal processing remain compromised. These immature synaptic properties would be expected to compound the inadequacies present in the cochlea and cochlear nucleus.

IKey words: inhibition, excitation, development, auditory pathways, lateral superior olive, synaptic integration, gerbil]

The development of neuronal connections and synaptic function derives primarily from studies on excitatory systems, even though inhibition plays an equivalent role in the function of neural

\footnotetext{
Received Sept. 2, 1992; revised Dec. 18, 1992; accepted Dec. 28, 1992.

I gratefully acknowledge Mr. Muh-lin Liou for expert design of the automated stimulation, acquisition, and analysis software used in this study, and Dr. Christopher Leonard for several helpful discussions. This work was supported by NIH Grant DC00540.

Correspondence should be addressed to Dan H. Sanes, Center for Ncural Science, 6 Washington Place, New York University, New York, NY 10003

Copyright (C) 1993 Society for Neuroscience $0270-6474 / 93 / 132627-11 \$ 05.00 / 0$
}

circuits and their maturation (Eccles, 1969; Oppenheim and Reitzel, 1975). The onset of excitatory transmission is significant because it provides trophic support for postsynaptic neurons and contributes to the stabilization of specific neuronal connections (Levi-Montalcini, 1949; Hubel and Wiesel, 1965; Hubel et al., 1977; Hyson and Rubel, 1989). These same issucs may also apply to inhibitory systems. For example, we have recently demonstrated an influence of inhibitory transmission on the maturation of postsynaptic dendrites and the refinement of single terminal arborizations (Sanes and Chokshi, 1992; Sanes et al., 1992b; Sanes and Takács, in press). Furthermore, improvements in excitatory transmission directly affect the maturation of sensory and motor integration. For neural circuits in which inhibition plays an essential role, its improved function is of equal relevance.

In the present study, the development of synaptic excitation and inhibition was compared in a brainstem auditory nucleus, the lateral superior olive (LSO). A major advantage of the LSO is the presence of an independent excitatory projection from the ipsilatcral cochlear nucleus (CN), and an inhibitory projection from the medial nucleus of the trapezoid body (MNTB) that is normally activated by the contralateral ear (Rasmussen, 1946; Morest, 1968; Browner and Webster, 1975; Tolbert et al., 1982; Moore and Caspary, 1983; Glendenning et al., 1985; Spangler et al., 1985; Cant and Casseday, 1986; Zook and DiCaprio, 1988). The LSO is the first auditory center to process sound level differences between the two ears (Boudreau and Tsuchitani, 1970; Caird and Klinke, 1983; Harnishfeger et al., 1985; Sanes and Rubel, 1988). An in vitro slice preparation through the ventral auditory brainstem has previously allowed for the independent examination of central synaptic properties in the LSO of mature animals (Sanes, 1990).

The gerbil auditory system develops rapidly, responding to airborne sound by approximately postnatal day 12 , and reaching functional maturity between postnatal days 16-30, depending on the property being analyzed (Finck et al., 1972; Harris and Dallos, 1984; Woolf and Ryan, 1984, 1985; Ryan and Woolf, 1988; Sanes and Rubel, 1988; Sanes et al., 1989). The development of LSO neuron form is also largely achieved during the first 3 postnatal weeks (Sanes et al., 1992a). We have previously described several aspects of inhibitory development in this system including its contribution to sound-evoked coding properties, the quantitative distribution of glycine receptors, and the specificity of single MNTB arbors along the tonotopic axis of the LSO (Sanes et al., 1987; Sanes and Rubel, 1988; Sanes and Siverls, 1991). All of these parameters indicate that inhibition is more pronounced during the first 2 postnatal weeks, and undergoes modification to reach a mature state. 
There are few studies devoted to the maturation of synaptic properties in the central auditory system. Neurons in the mouse $\mathrm{CN}$ exhibit a greater synaptic latency and more prominent fatigue to repeated stimulation in animals younger than $13 \mathrm{~d}$ postnatal (Wu and Ocrtel, 1986). A developmental decrease in the number of converging afferents has also been demonstrated electrophysiologically in the avian CN (Jackson and Parks, 1982), and there is a developmental gradient of synaptic function in this structure such that the basalmost projection region is the first to respond (Jackson et al., 1982).

The following experiments demonstrated that synaptic excitation and inhibition were present at birth, but exhibited a number of atypical responses during the first 2 postnatal weeks. In particular, the temporal properties of these synaptic potentials profoundly effected their integration by LSO neurons, suggesting central limitations on binaural intensity difference coding during development. The extended durations of synaptic potentials, and the presence of IPSP-evoked rebound depolarizations indicated that activity-mediated processes, such as those implicated in the maturation of excitatory projections, are feasible for developing inhibitory afferents within the LSO.

\section{Materials and Methods}

Brain slice preparation. Gerbils (Meriones unguiculatus) aged 1-15 d postnatal were first deeply anesthetized (hypothermia for animals 1-8 d postnatal, and $800 \mathrm{mg} / \mathrm{kg}$ chloral hydrate for animals $9-15 \mathrm{~d}$ postnatal), and then decapitated. The brain was rapidly dissected free in oxygenated artificial cerebrospinal fluid (ACSF: $\mathrm{NaCl}, 127.4 \mathrm{~mm} ; \mathrm{KCl}$, $5 \mathrm{~mm} ; \mathrm{KH}_{2} \mathrm{PO}_{4}, 1.2 \mathrm{~mm}$; $\mathrm{MgSO}_{4}, 1.3 \mathrm{~mm} ; \mathrm{NaHCO}_{3}, 26 \mathrm{~mm}$; glucose, $\left.15 \mathrm{~mm} ; \mathrm{CaCl}_{2}, 2.4 \mathrm{~mm} ; \mathrm{pI} 7.4\right)$ at $10-15^{\circ} \mathrm{C}$. The brainstem was trimmed and mounted on a piece of agar in a Petri dish with cyanoacrylate glue, and sectioned at $400-450 \mu \mathrm{m}$ with a vibratome (TPI series 1000 ). The sections were transferred to a holding chamber containing oxygenated ACSF, and allowed to warm to room temperature for 30-60 min. The sections were then transferred to a custom-designed recording chamber with a flow rate of $8 \mathrm{ml} / \mathrm{min}$, and the temperature was gradually raised to $31-32^{\circ} \mathrm{C}$.

Electrical stimulation. Two bipolar stimulating electrodes were lowered to contact the brainstem at the MNTB and just lateral to the facial nerve on the ventral surface (i.c., on afferents from the ipsilateral cochlear nucleus). The positions were approximately equidistant from the recording site within the LSO. Electrical stimuli were delivered either manually (Grass S11) or via computer control (Everex 386, RC Electronics), both of which were isolated from ground (Intronix). Individual pulses were $100 \mu \mathrm{sec}$ in duration, and the voltages typically ranged from 1 to $30 \mathrm{~V}$. When feasible, $200 \mathrm{msec}$ current pulses were delivered through the recording electrode, and the voltage across the membrane was monitored to yield current-voltage relationships.

Intracellular recording. Intracellular pipettes were filled with $2 \mathrm{M}$ potassium citrate, and had resistances between 140 and $180 \mathrm{M} \Omega$. Electrodes were positioned over the LSO and advanced (Burleigh) in $0.5 \mu \mathrm{m}$ steps while monitoring membrane voltage (Axoprobe $1 \mathrm{~A}$ ). The impalement of a neuron was verified by observing whether synaptic potentials were evoked by stimuli to the MNTB or CN afferents. Since stable recordings are more difficult to obtain from very young animals ( $1-6 \mathrm{~d}$ postnatal), all neurons with a resting potential greater than $-45 \mathrm{mV}$ were accepted for analysis. The criteria resting potential was $-50 \mathrm{mV}$ for neurons from animals $7-15 \mathrm{~d}$ postnatal. The present data set draws on recordings from 70 neurons in 38 animals.

Acquisition and analysis. Stimulus-evoked responses were digitized at $10 \mathrm{kHz}$ and stored directly on a computer $(33 \mathrm{MHz}$ PC AT; ComputerBoards CIO-AT $16 \mathrm{Jr}-\mathrm{AT}$ ) for off-line analysis. The stored traces were analyzed with custom-designed software that allowed for the selection of individual traces, and the computation of slope, duration, latency, amplitude, and area between a postsynaptic potential (PSP) and the resting baseline. The latter measure was used to estimate convergence of afferents, as was described previously for more mature animals (Sanes, 1990).

The algorithm for determining quantized increases in PSP size consisted of grouping the traces together based upon area differences. In- cremental stimulus amplitudes were delivered to the ipsilateral or contralateral pathway to recruit a successively greater number of afferents, producing successively large PSPs. After integrating under cach PSP, the smallest area PSP was compared to the next larger one. If the area of the larger PSP did not exceed the average area noise that was present just prior to the stimulus pulse, then the traces were grouped together. The measure of area noise was multiplied by the duration of the PSPs being compared. When the area of a PSP exceeded that of the first PSP by a value greater than the average area noise, a new group was started.

\section{Results}

\section{Response to current injection}

The current-voltage relationships for nconatal and mature animals did not appear to differ significantly. As shown in Figure 1 , there was a linear response to inward current pulses, and a nonlinear response to outward current pulses, suggesting a delayed-rectifying current. In animals $1-7 \mathrm{~d}$ postnatal, the mean input resistance, $R_{\text {inpul }}$, was $64 \pm 5 \mathrm{M} \Omega$, and the mean time constant, $\tau$, was $8.8 \pm 1.2 \mathrm{msec}( \pm \mathrm{SEM} ; N=11)$. In animals 8-14 d postnatal, the mean $R_{\text {input }}$ was $42 \pm 8.5 \mathrm{M} \Omega$, and the mean $\tau$ was $3.8 \pm 0.6 \mathrm{msec}(N=8)$. There was a significant decrease in both $R_{\text {input }}$ and $\tau$ from $1-7$ to $8-15 \mathrm{~d}(t=2.32, p=$ 0.033 and $t=3.42, p=0.003$, respectively), and a significant decrease for $\tau$ from $8-15$ to $17-23 \mathrm{~d}(\tau=1.1 \mathrm{msec} ; N=11 ; t$ $=4.96, p=0.0005)$. As indicated by the arrows in Figure 1 , there were voltage oscillations to outward current pulses in some neurons from younger animals. The MNTB-evoked IPSP reversal potential was nearly identical to that of older animals (Sanes, 1990), varying between -69 and $-73 \mathrm{mV}$ in $2-6 \mathrm{~d}$ animals $(N=5)$.

\section{PSPS}

The most obvious change in PSPs was in their time course. Figure $2 A$ illustrates a family of excitatory and inhibitory responses from neurons at five different postnatal ages. Figure $2 B$ summarizes this data, and illustrates that there was a dramatic decrease in maximum PSP duration from 1 to $12 \mathrm{~d}$ postnatal, and a moderate decrease thereafter. For example, the mean maximum IPSP duration at $8-15 \mathrm{~d}$ was $21.2 \pm 2.2 \mathrm{msec}(N=$ $32)$, while the value at $17-23 \mathrm{~d}$ was $8.1 \pm 0.7 \mathrm{msec}(N=19$; Sanes, 1990). It should be noted that in a few young animals MNTB-evoked IPSPs could rapidly decline in amplitude or actually reverse their polarity without a change in the resting potential. Data from these neurons were not included in the present study because the IPSP reversal could have resulted from either injury during impalement or a fragile $\mathrm{Cl}$ transport mechanism (Luhmann and Prince, 1991).

The duration of single evoked EPSPs and IPSPs led to a profound temporal summation during brief trains of electrical stimuli (Fig. 3). The $100 \mathrm{~Hz}$ stimulus trains led to a maintained depolarization or hyperpolarization during the first postnatal week. In contrast, discrete evoked PSPs were present by the third postnatal week. The temporal summation in neonatal animals could have obscured synaptic fatigue that was clearly present in neurons from older animals (Fig. 3).

During the first $1-4$ postnatal days, it was possible to find excitatory responses to pulse trains that lasted far beyond the stimulus period. Figure 4 illustrates three cases in which the membrane potential remained depolarized from rest for several hundred milliseconds following the short train $(\approx 70 \mathrm{msec})$ of electrical stimuli. An extended hyperpolarization, comparable to this response, was never observed following a short stimulus train to the MNTB. 
2 day

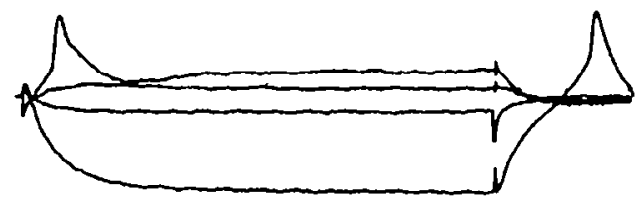

6 day

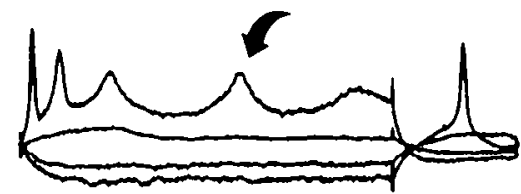

12 day

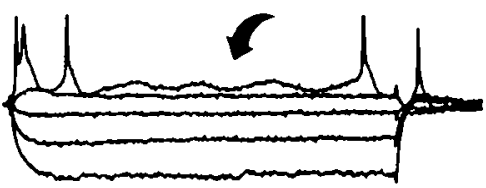

20 day
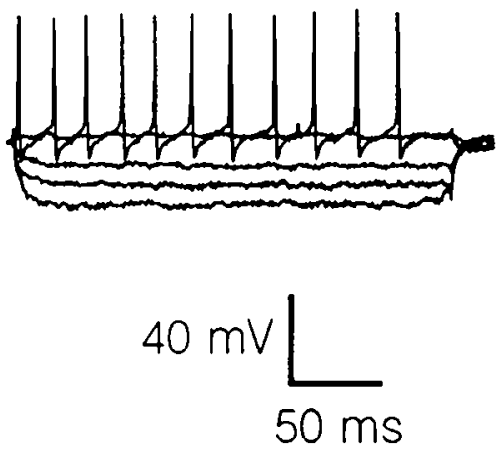

The synaptically elicited action potentials were far more variable in latency during the first 2 postnatal weeks. Figure 5 illustrates characteristic responses at three different postnatal ages, demonstrating the consequences of temporal summation and fatigue. On average, the mean minimum response latency decreased slightly during development (Table 1), but factors such as electrode placement cannot be ruled out as contributing to the effect.

There was a large increase in the rising slope of both EPSPs and IPSPs (Table 1). For example, the mean maximum rising slope of IPSPs gradually increased from $6.5 \pm 0.7 \mathrm{mV} / \mathrm{msec}$ at 1-7 d $(N=18)$, to $8.2 \pm 0.8 \mathrm{mV} / \mathrm{msec}$ at $8-15 \mathrm{~d}(N=32)$, and $9.8 \pm 1.2 \mathrm{mV} / \mathrm{msec}$ at $17-23 \mathrm{~d}(N=20$; Sanes, 1990). The mean amplitude of EPSPs and IPSPs was examined with respect to both age and resting potential, since the data set from younger animals was biased toward lower resting potentials (see Materials and Methods). For neurons with resting membrane potentials in a limited range ( $V_{\text {rest }}$ from -55 to $-65 \mathrm{mV}$ ), the mean maximum IPSP amplitude in animals $1-14 \mathrm{~d}$ postnatal $(N=$ 14) was significantly greater than that in animals $17-23 \mathrm{~d}$ post-
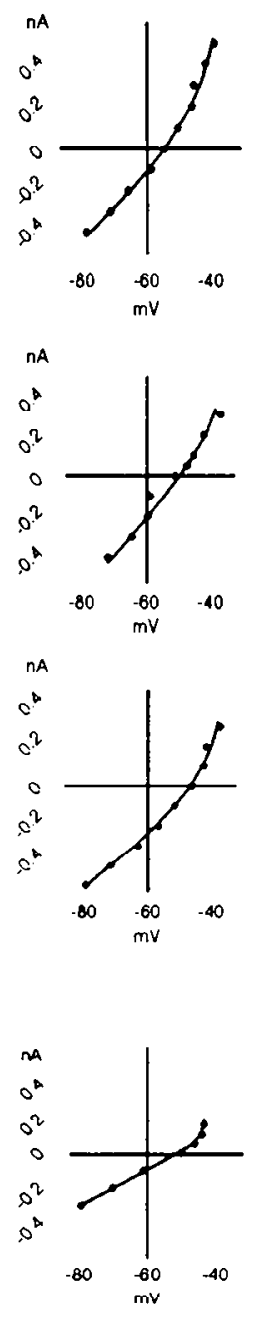

natal ( $10.2 \mathrm{mV}$ vs $6.4 \mathrm{mV} ; t-2.66, \mathrm{df}-20, p-0.015)$. There was no significant difference for mean resting membrane potential for this subpopulation, suggesting that the amplitude difference was of developmental origin.

There was one additional synaptic phenomenon that was apparent in neurons from 1-8 d animals. As shown in Figure 6, single stimuli or short trains delivered to the MNTB could evoke a sizable hyperpolarization that led to a long-lasting depolarization or action potential. It was extremely unlikely that this depolarization was due to the concomitant stimulation of excitatory afferents because an inward current pulse that was sufficient to reverse the IPSP eliminated any sign of depolarization at the same latency, but did itself evoke a rebound action potential when the current pulse ended (Fig. 6, top).

An estimate of the number of converging MNTB or CN afferents was obtained by calculating the area between each PSP and the resting baseline (Sanes, 1990). As shown in Figure 7, there was an apparent decrease in the number of afferents from both sources during the first 3 postnatal weeks. For example, there was a significant decrease in the number of quantized 
Figure 2. Development of PSP duration. $A, \mathrm{~A}$ family of excitatory and inhibitory synaptic responses are shown for single neurons at five different ages. Electric stimuli were applied to the $\mathrm{CN}$ and MNTB, respectively. A stimulus artifact occurs prior to each set of PSPs (arrowheads). B, A summary of the maximum EPSP and IPSP durations is shown along with the mean value (asterisks) from animals aged 17-23 d postnatal (Sanes, 1990). There was a dramatic decrease in PSP duration from $1-12 \mathrm{~d}$.
A
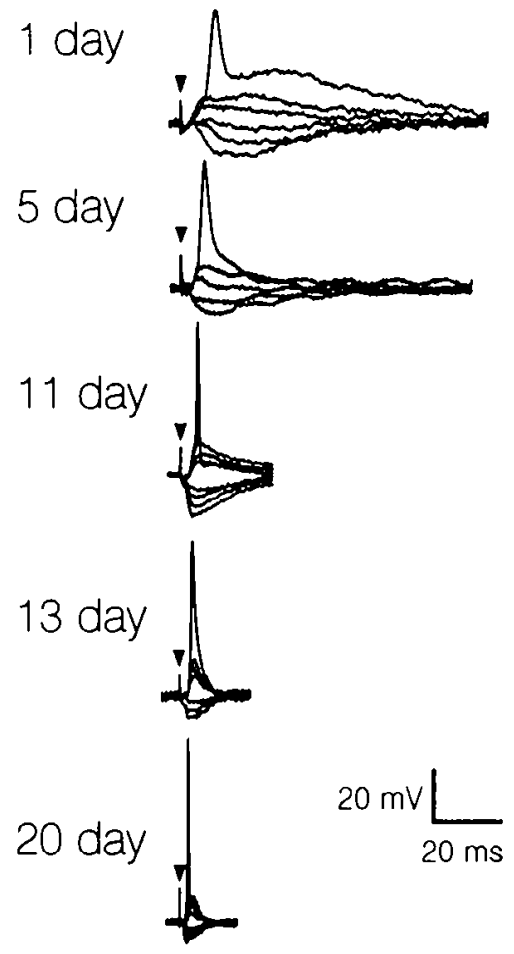
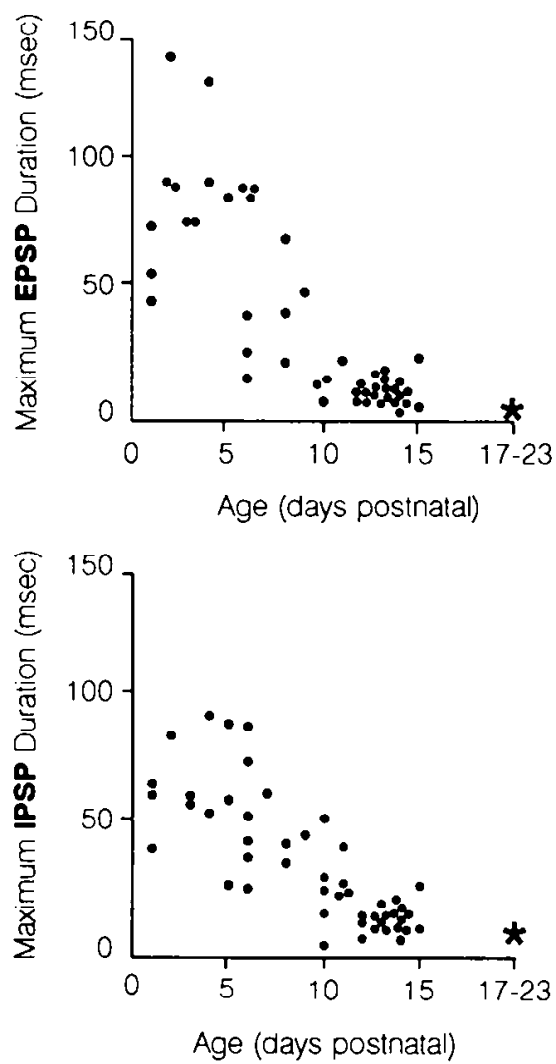

increases in IPSP area from a value of $15.5 \pm 1.0(N=15)$ at $1-7 \mathrm{~d}$ to $8.7 \pm 0.7(N=19)$ at $17-23 \mathrm{~d}(t=5.81, \mathrm{df}=32, p<$ 0.001 ).

\section{Synaptic integration}

The effective duration of an IPSP was evaluated by observing whether it blocked a synaptically evoked action potential at different points in its time course. The action potential latency was successively delayed with respect to that of the IPSP. As shown in Figure 8, the IPSPs in young animals were not only longer in duration but, more importantly, were able to suppress an action potential for an extended period of time. Compared to recordings from 17-23 d animals (Sanes, 1990), the period of suppression was 1-2 orders of magnitude longer in 1-14 d animals.

The effect of stimulus level on synaptic integration was evaluated by varying the voltage pulse to either the ipsilateral excitatory or contralateral inhibitory pathway. As shown in Figure 9 , an increase in the contralateral stimulus led to a doubling in the time during which the IPSP was able to suppress an ipsilaterally evoked action potential. Increments in stimulus level to the ipsilateral pathway continued to evoke a single action potential, but decreased the time during which the contralaterally evoked IPSP suppressed the action potential (Fig. 10).

The level-dependent increase in action potential efficacy could limit the duration of suppression at both the onset and offset of the MNTB-evoked IPSP, as demonstrated by a recording from a $12 \mathrm{~d}$ neuron (dashed arrows in Fig. 11). In this case, the increase in ipsilateral stimulus level led to a decrease in the suppression time from 9.1 to $6.4 \mathrm{msec}$. In a $14 \mathrm{~d}$ neuron, a slight increase in contralateral stimulus level led to a doubling of the suppression time, from 7.3 to $15 \mathrm{msec}$ (Fig. 11). As was true of the $12 \mathrm{~d}$ neuron, the duration of suppression was flexible at both the onset and offset of the MNTB-evoked IPSP. A small decrease in ipsilateral stimulus level from 7 to $6 \mathrm{~V}$ led to the failure of a short-latency ipsilateral stimulus to evoke an action potential at the leading edge of the IPSP (see curved arrow in Fig. 11). Although the quantitative effect of stimulus level dependence varied from neuron to neuron, the IPSPs were usually able to suppress action potentials for a much longer period of time in $1-14 \mathrm{~d}$ animals, compared to $17-23 \mathrm{~d}$ animals.

\section{Discussion}

Developmental improvements in an animal's perceptual capacity are fundamentally limited by the maturity of the periphcral sense organ. Therefore, it is often necessary to demonstrate a temporal disparity between the maturation of the PNS and CNS in order to understand the contribution of each. The present study has circumvented this difficulty by directly assessing the synaptic properties of a central auditory circuit. The results support the view that alterations in synaptic transmission and integration have an impact on auditory processing in the LSO during postnatal maturation. These signs of synaptic development are fully consistent with previous studies demonstrating a developmental improvement of auditory coding properties in single LSO neurons (Romand et al., 1973; Sanes and Rubel, 1988), an alteration in the distribution of glycine receptors in the LSO (Sanes and Wooten, 1987), a refinement of single MNTB arborizations within the LSO (Sanes and Siverls, 1991), and a refinement of LSO dendritic arborizations (Sanes et al., 1992a). The immaturc properties noted above would be expected to 


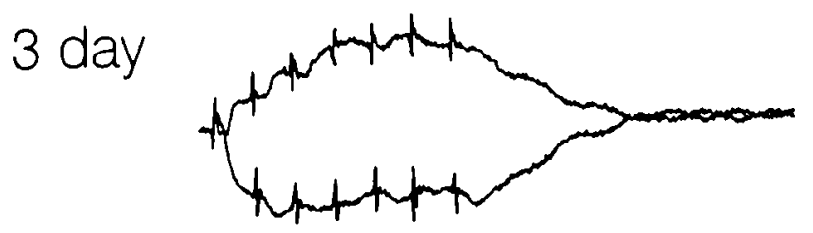

6 day

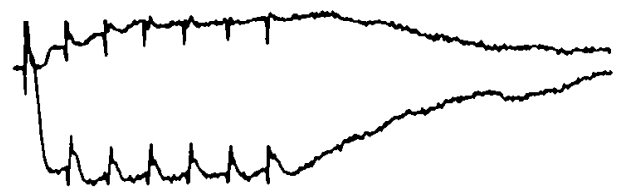

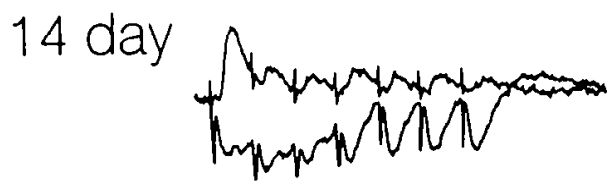

20 day
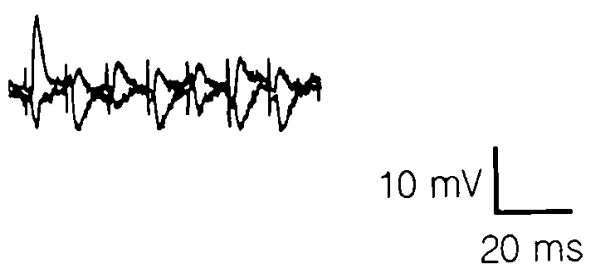

Figure 3. Temporal summation. The excitatory and inhibitory responses to a short $100 \mathrm{~Hz}$ train of stimuli applied to the CN and MNTB, respectivcly, are shown for single neurons at four different ages. In the recordings from 3 and $6 \mathrm{~d}$ animals, the temporal summation led to a continuous shift of the membrane potential during the stimulus train. At $14 \mathrm{~d}$, there was some indication of temporal summation, particularly during the first three pulses to the inhibitory pathway. At $20 \mathrm{~d}$, temporal summation was extremely rare. Note that there was a striking fatigue of the excitatory pathway, but not the inhibitory pathway, at 14 and 20 d. Stimulus artifacts appear as short vertical lines within each record.

degrade further the neural information passed along from the cochlea and cochlear nuclei.

\section{Development of inhibition and synaptic integration in the LSO}

The favorable architecture of the superior olive allowed for an independent analysis of synaptic excitation and inhibition. The results were consistent with an early onset of synaptic function, and a more prominent appearance in neonates. Several in vivo studies also support the early appearance of functional inhibition in the central auditory system (Romand et al., 1973; Woolf and Ryan, 1985; Sanes and Rubel, 1988). Stimulation of the MNTB evoked hyperpolarizing synaptic potentials as early as 1 d postnatal. Difficulties in obtaining timed pregnant gerbils prevented an examination of synaptic function in prenatal animals. The IPSPs were generally larger in neonates, although these sizable potentials may have been an artifact of the lower resting membrane potentials in young animals. However, a comparison of amplitude among a subset of neurons with similar resting potentials also revealed a difference with age. It is possible that the larger amplitudes observed in neonates resulted from a greater number of afferents per LSO neuron (Fig. 7). There was no apparent change in the IPSP reversal potential with postnatal age, however, indicating an equivalent driving
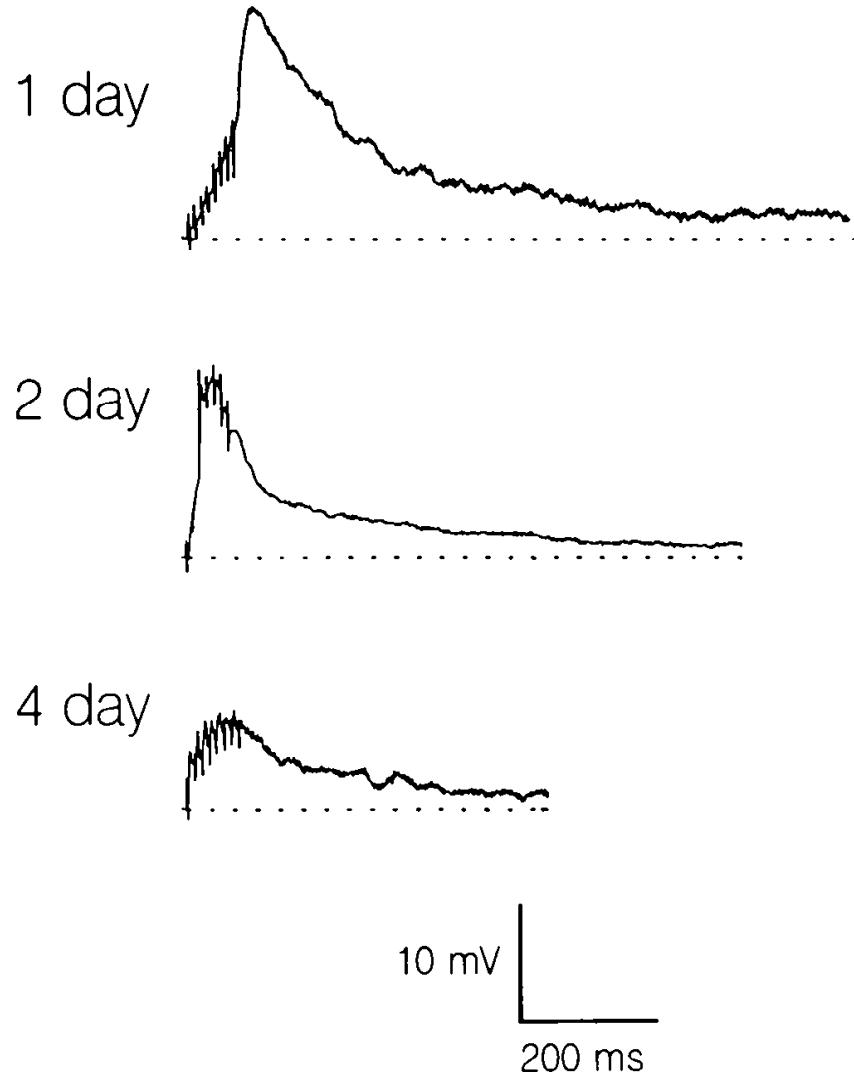

Figure 4. Prolonged depolarizations in neonates. Short trains of electrical stimuli $(100 \mathrm{~Hz}$ for $70 \mathrm{msec})$ delivered to the $\mathrm{CN}$ resulted in extremely long-lasting depolarizations of the LSO neuron. All traces eventually returned to the resting baseline (dotled line), but this occurred gradually, and could exceed $1 \mathrm{sec}$. The stimulus artifacts appear as short vertical lines during the first $100 \mathrm{msec}$ of each trace.

force for MNTB-evoked potentials. The reversal potential for IPSPs has been shown to remain constant during cortex development (Komatsu and Iwakiri, 1991), although it does increase in the hippocampus (Luhmann and Prince, 1991).

The IPSPs from animals $1-15 \mathrm{~d}$ showed three signs of immaturity in the time domain. First, the duration of a single response was up to 100 times longer at $1-7 \mathrm{~d}$ postnatal (Fig. 2). While it is possible that the neurons time constant could have contributed to longer PSP durations, it is clear that a $\tau$ of 8.8 msec could not explain a PSP duration of $78 \mathrm{msec}$ (the mean values for 1-7 d postnatal). Second, both the latency to rise above the resting baseline, and the latency to reach peak amplitude were two to five times longer at 1-7 d, compared to 17$23 \mathrm{~d}$ animals (Table 1; Sanes, 1990). Although latency can be related to electrode placement, the smaller size of the auditory brainstem in younger animals (Sanes and Wooten, 1987) would ensure that the stimulating electrodes were closer to the recording site, thus biasing the latency toward shorter values. Finally, the rising slope increased significantly with age (Table 1; Sanes, 1990). The steeper rise time would presumably be important for time-critical binaural integration.

Short trains of stimuli to the MNTB (e.g., $100 \mathrm{~Hz}$ for $70 \mathrm{msec}$ ) generally led to a temporal summation of PSPs such that LSO neurons were hyperpolarized for a period far exceeding the stimulus train duration (Fig. 3). Fatigue of axonal conductance or synaptic transmission was clearly overridden by this summation. It is not presently clear how realistic these short trains of 

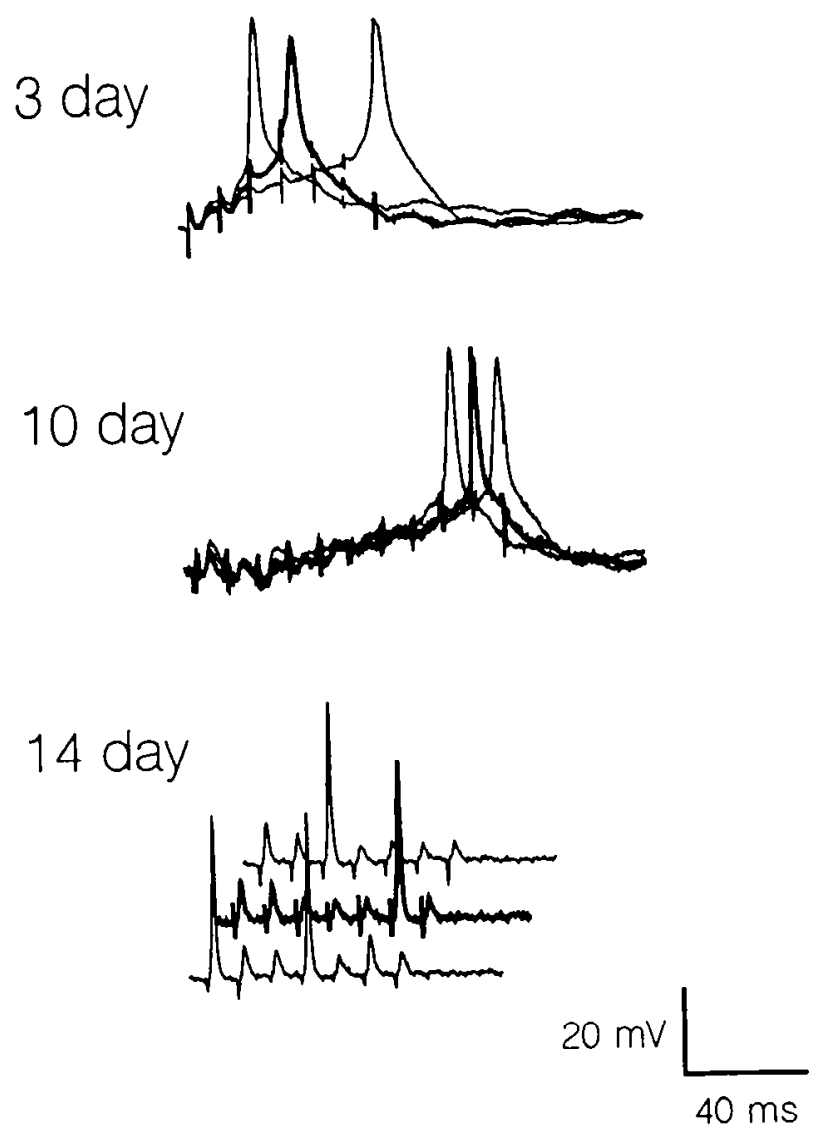

Figure 5. Temporal ambiguity of the response. Three traces are each shown for neurons at 3,10, and $14 \mathrm{~d}$ postnatal, in response to short trains of stimuli to the excitatory afferents. At each age, identical stimulus conditions led to extremely variable latency of action potentials. Although there was not temporal summation in the $14 \mathrm{~d}$ animal, the action potentials were evoked by different stimuli in each of the three trains. For each set of traces, one of them is shown in bold for clarity.

stimuli are. Although there are periods of maintained discharge in the developing central auditory system prior to, or in the absence of, a response to airborne sound (Lippe, 1984; Sanes, 1984), the maximum instantaneous discharge rate has not been detcrmined.

Evoked IPSPs were large enough to result in a rebound depolarization or action potential (Fig. 6). It was extremely unlikely that this long-latency (e.g., $>50 \mathrm{msec}$ ) cxcitatory response was due to a second synaptic input that was recruited by the stimulus pulse to the MNTB. There is no known pathway contained within the ventral auditory brainstem that could yield such a long-latency response. Moreover, it was found that inward current sufficient to reverse the IPSP did not enhance the depolarizing response (Fig. 6). Although the present study does not address the ionic basis for such a rebound excitatory response, it is consistent with a low-threshold $\mathrm{Ca}^{2+}$ current (Llinás and Yarom, 1981).

The integration of synaptic inputs from the CN and the MNTB was directly assessed in LSO neurons by determining whether a synaptically evoked action potential could be suppressed at successive times during the IPSPs time course (Coombs et al., 1955; Curtis and Eccles, 1959). It was found that IPSPs in younger animals were able to block action potentials for the majority of their time course, up to 1-2 orders of magnitude longer than in more mature animals (Fig. 8). It is known from
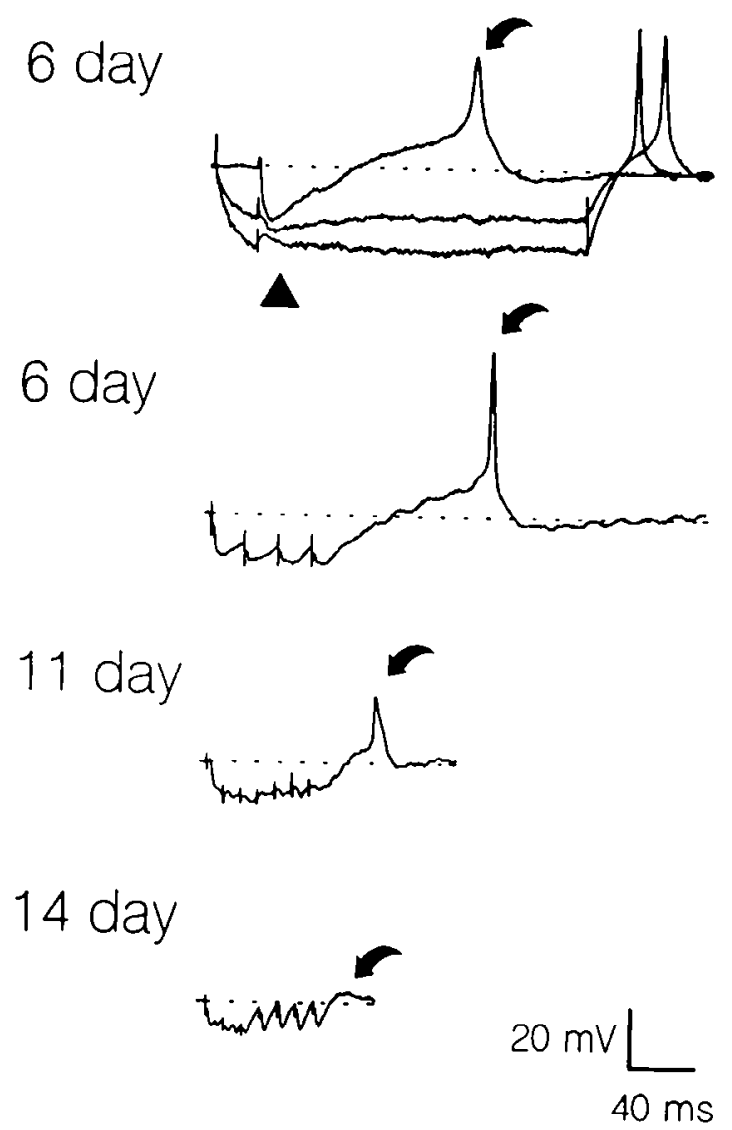

Figure 6. Synaptically evoked hyperpolarizations elicit an action potential in neonates. Recordings from four different neurons demonstrated that single or multiple MNTB-evoked IPSPs were often followed by a long-latency action potential or depolarization (arrows). The top set of traces show that inward current reversed the MNTB-evoked IPSP (arrowhead), and eliminated the latent depolarization rather than accentuating it.

voltage-clamp studies in the spinal cord that IPSP duration outlasts the increased conductance underlying it (Araki and Terzuolo, 1962). Thus, MNTB-evoked inhibition would be expected to clamp the neuron to the IPSP reversal potential for only a short period of time. The prolonged IPSP blockade of synaptically evoked action potentials suggests either that the glycine uptake system is less efficient (Zukin et al., 1975), or that there are markedly different glycine receptor kinetics in neonates (Akagi and Miledi, 1988).

There was a strong level dependence to the suppression of action potentials. In general, it was found that increasing ipsilateral stimulus level led to a concomitant decrease in the duration of suppression (Fig. 10). When stimulus level to the MNTB was increased there was a concomitant increase in the duration of suppression (Fig. 9). The level dependence of inhibition was apparent at both the onset and offset of the IPSP. For example, an increase in the ipsilateral stimulus level limited suppression at both the leading edge and terminal portion of the IPSP in a $12 \mathrm{~d}$ neuron (Fig. 11).

\section{Development of excitation in the LSO}

With few exceptions, the developmental characteristics of EPSPS and action potentials were similar to those of IPSPs. For example, duration and latency decreased with age, while rising slope increased (Table 1; Sanes, 1990). Although peak amplitude 


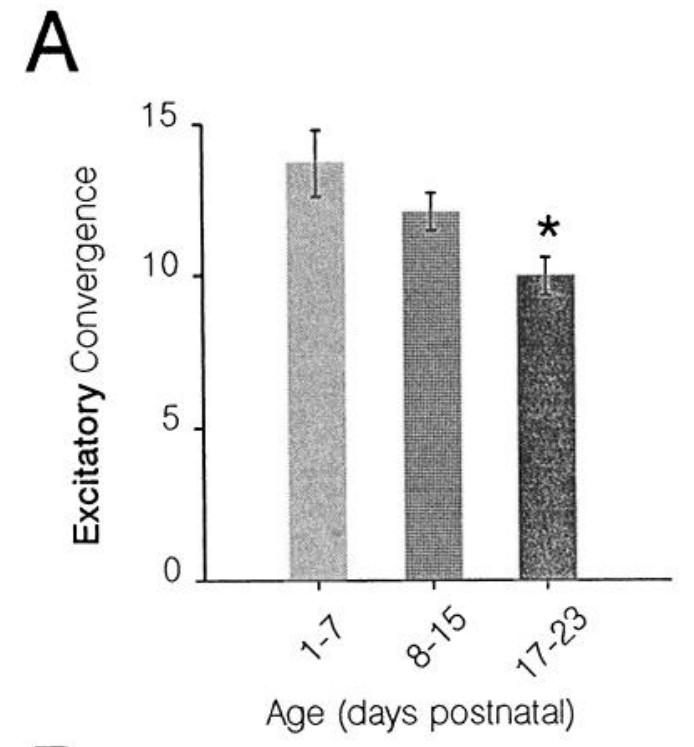

B

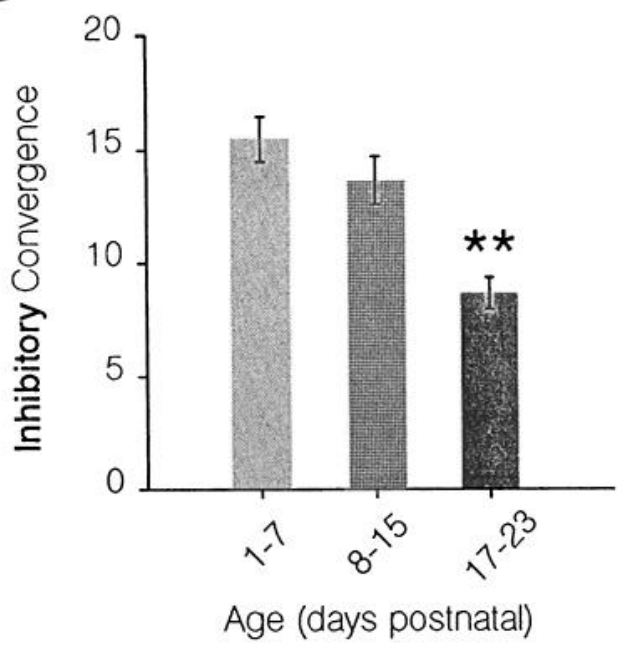

Figure 7. Decrease in the number of converging afferents. An estimate of the number of converging excitatory $\mathrm{CN}$ afferents $(A)$ or inhibitory MNTB afferents $(B)$ was made based upon quantized increases in PSP size to stimuli of increasing voltage (see Materials and Methods). There was a significant decrease in this value for both sets of afferents, suggesting the elimination of afferents during development. The mean and SEM are shown for each group $\left(^{*}\right.$, significantly less than value for $1-7$ $\mathrm{d}$ group at $p<0.01$, and $8-15 \mathrm{~d}$ group at $p<0.05 ;{ }^{* *}$, significantly less than value for $1-7 \mathrm{~d}$ group at $p<0.001$, and $8-15 \mathrm{~d}$ group at $p<$ 0.005).

showed a slight decline with age, this was not significant. Action potentials significantly increased in amplitude, but this could have been due to more stable recordings in older animals. As with IPSPs, a short train of stimuli commonly led to temporal summation such that the LSO neuron was depolarized for a period exceeding the stimulus trains (Fig. 3).

There were three aspects of excitatory development in the LSO that require discussion. First, a short stimulus train (e.g., $100 \mathrm{~Hz}$ for $70 \mathrm{msec}$ ) could evoke an unusually long-lasting depolarization in neurons from $1-4 \mathrm{~d}$ animals (Fig. 4). This response far outlasted the decay time of a single EPSP. The pharmacological or ionic basis of this response is unknown, but its longevity could well have developmental repercussions at a time when neuronal discharge is limited (Spitzer, 1991). The
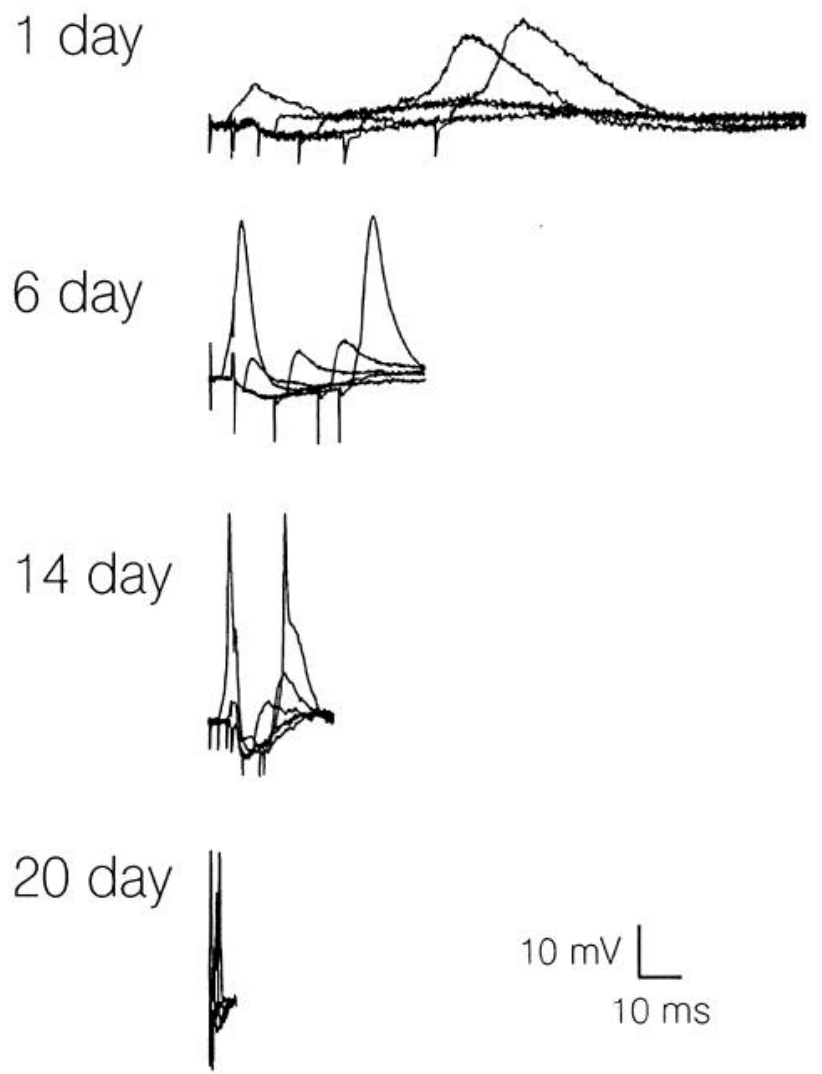

Figure 8. Synaptic integration. An ipsilaterally evoked action potential was elicited at different relative latencies to an MNTB-evoked IPSP to determine the duration of temporal integration at different ages. The action potential was blocked for a much longer period of time in neonatal animals compared to mature animals. For example, in the recording from a $1 \mathrm{~d}$ LSO neuron, the action potential was blocked for about 30 $\mathrm{msec}$. This efficacious period gradually declined to about $1 \mathrm{msec}$ in the neuron from a $20 \mathrm{~d}$ animal.

second issue concerns the manner in which temporal summation of EPSPs led to an action potential. In younger animals, there was a large variability of action potential appearance and latency when identical stimulus trains were applied (Fig. 5). This suggests that equivalent stimuli, or afferent discharge patterns, do not have a robust representation in the developing nervous system, particularly for those computations that require some degree of temporal acuity. The final matter concerns EPSP amplitude, which was generally found to show greater signs of fatigue, compared to IPSPs, only in older animals (Fig. 3). Although this phenomenon will be the focus of a future investigation, its developmental emergence conveys the range of synaptic alterations that may contribute to the maturation of central auditory processing.

\section{Comparison to inhibitory development in other systems}

Synaptic inhibition is commonly accepted as a mechanism for contouring the neural response properties set forth by excitatory afferents. Therefore, the development of specific inhibitory connections, and their activity-dependent modulation are of fundamental importance to neural function. The behavioral appearance of inhibition may lag only $24 \mathrm{hr}$ behind excitatory mechanisms in the chick spinal cord (Bekoff et al., 1975; Oppenheim and Reitzel, 1975). Several electrophysiology studies reveal a somewhat more latent appearance of neural inhibition 


\begin{tabular}{|c|c|c|c|}
\hline & EPSPs (SEM) & IPSPs (SEM) & $\mathrm{AP}^{a}(\mathrm{SEM})$ \\
\hline \multicolumn{4}{|l|}{ Summary of synaptic properties at $1-7 \mathrm{~d}$} \\
\hline Maximum latency to rise (msec) & $5.0 \pm 0.4^{*}$ & $6.8 \pm 0.6^{*}$ & $14.4 \pm 2.2^{\circ}$ \\
\hline Minimum latency to peak (msec) & $6.2 \pm 0.6^{*}$ & $6.8 \pm 0.4^{*}$ & $9.0 \pm 1.7^{b}$ \\
\hline Maximum latency to peak (msec) & $25.9 \pm 3.7^{*}$ & $21.0 \pm 1.4^{*}$ & $17.0 \pm 2.5^{\prime \prime}$ \\
\hline Minimum duration (msec) & $16.3 \pm 3.2^{*}$ & $14.5 \pm 1.3^{*}$ & $5.7 \pm 1.1^{\circ}$ \\
\hline Maximum duration (msec) & $78.6 \pm 8.1^{*}$ & $61.8 \pm 4.8^{*}$ & $13.4 \pm 3.8^{b}$ \\
\hline Minimum amplitude (mV) & $1.9 \pm 0.2$ & $2.0 \pm 0.2$ & $30 \pm 5$ \\
\hline Maximum amplitude (mV) & $10.0 \pm 0.8$ & $11.1 \pm 1.0$ & $36 \pm 5$ \\
\hline Minimum slope ( $\mathrm{mV} / \mathrm{msec})$ & $1.7 \pm 0.2$ & $1.8 \pm 0.3$ & $15.3 \pm 7.4$ \\
\hline Maximum slope ( $\mathrm{mV} / \mathrm{msec})$ & $5.8 \pm 0.6^{*}$ & $6.5 \pm 0.7$ & $24.7 \pm 8.2$ \\
\hline \multicolumn{4}{|c|}{ Summary of synaptic properties at $8-15 \mathrm{~d}$} \\
\hline Maximum latency to rise (msec) & $3.6 \pm 0.1^{*}$ & $3.4 \pm 0.2$ & $5.6 \pm 0.3^{b}$ \\
\hline Minimum latency to peak (msec) & $3.9 \pm 0.2^{*}$ & $3.9 \pm 0.3$ & $4.3 \pm 0.2^{b}$ \\
\hline Maximum latency to peak (msec) & $6.8 \pm 0.4^{*}$ & $8.3 \pm 0.7^{*}$ & $6.1 \pm 0.4^{b}$ \\
\hline Minimum duration (msec) & $4.9 \pm 0.9^{*}$ & $6.4 \pm 0.8^{*}$ & $1.4 \pm 0.1^{b}$ \\
\hline Maximum duration (msec) & $17.0 \pm 2.4^{*}$ & $21.2 \pm 2.2^{*}$ & $2.0 \pm 0.3^{h}$ \\
\hline Minimum amplitude (mV) & $1.6 \pm 0.2$ & $2.1 \pm 0.3$ & $40 \pm 2$ \\
\hline Maximum amplitude $(\mathrm{mV})$ & $9.7 \pm 0.6$ & $9.5 \pm 0.7$ & $45 \pm 2$ \\
\hline Minimum slope ( $\mathrm{mV} / \mathrm{msec})$ & $1.8 \pm 0.2$ & $2.1 \pm 0.4$ & $54.4 \pm 3.9$ \\
\hline Maximum slope $(\mathrm{mV} / \mathrm{msec})$ & $9.0 \pm 0.6$ & $8.2 \pm 0.8$ & $70.3 \pm 3.8$ \\
\hline
\end{tabular}

\footnotetext{
Action potentials

${ }^{B}$ Measures for action potentials taken at half-maximum amplitude.

* Significantly different from value in older age group at $p<0.05$.
}

\section{6 day}
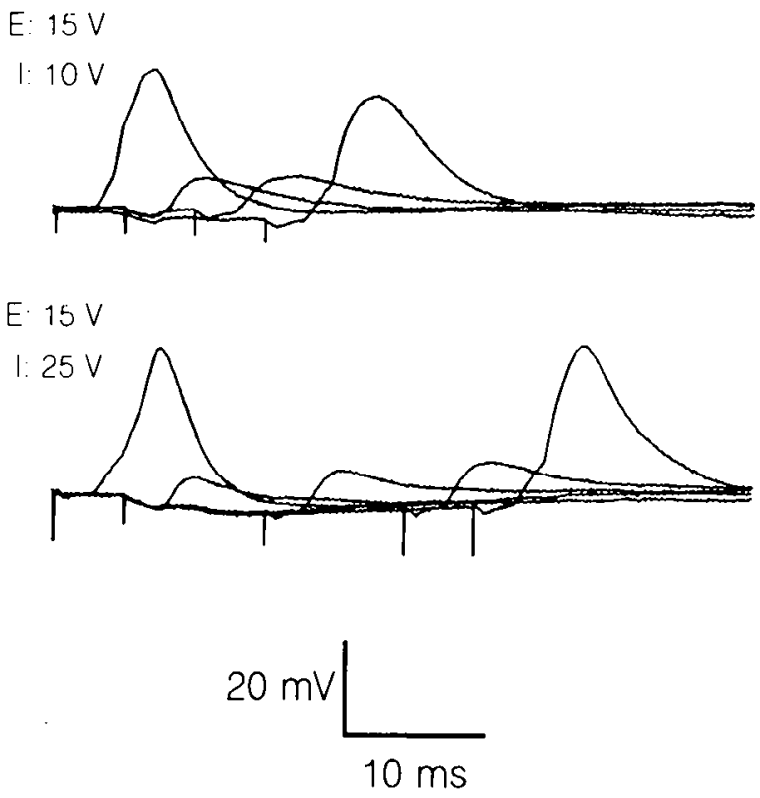

Figure 9. The duration of inhibition is level dependent at $6 \mathrm{~d}$ postnatal. An ipsilaterally evoked action potential was advanced through an MNTBevoked IPSP at two different contralateral stimulus levels. When the contralateral stimulus voltage was raised from 10 to $25 \mathrm{~V}$, the duration of suppression increased from $15.5 \mathrm{msec}$ to $29.5 \mathrm{msec}$ ( $E$, stimulus voltage to ipsilateral pathway; $I$, stimulus voltage to contralateral pathway).
(Maximova, 1971; Schwartzkroin and Kunkel, 1982; Komatsu, 1983; Shatz and Kirkwood, 1984; Fitzgerald and Koltzenberg, 1986; Luhmann and Prince, 1991). After neural inhibition does appear, however, its efficacy may be elevated relative to that of excitatory systems (Krnjevic et al., 1964; Purpura et al., 1965; Persson, 1973; Schwob et al., 1984; Wilson and Leon, 1986; Sanes and Rubel, 1988).

The alterations in PSP size and duration in the LSO were not unexpected. In fact, a decrease in the duration of PSPs has been documented in a wide variety of central neuronal systems (Naka, 1964; Purpura et al., 1965; Schwob et al., 1984; Gardette et al., 1985; Wilson and Leon, 1986). We have previously shown that the transmitter receptor molecule mediating neural inhibition in the LSO, the glycine receptor, undergoes a change in distribution during postnatal development (Sanes and Wooten, 1987), and that the inhibitory arbors from the MNTB exhibit a period of refinement during the third postnatal week (Sanes and Siverls, 1991).

The neonatal appearance of synaptic inhibition and excitation in the LSO is obvious at birth, although it would be necessary to record from prenatal tissue in order to determine if either synapse type became functional prior to the other. Nevertheless, the appearance of synaptic inhibition precedes sound-evoked responses by approximately 2 weeks. The early appearance and prominence of inhibition suggest that it may have an influence on other aspects of neural development, as has been shown for excitatory systems (Larsell, 1931; Levi-Montalcini, 1949).

In neonatal animals, a rebound depolarization was observed following the MNTB-evoked hyperpolarization. A long-latency "rebound" depolarization following an evoked IPSP has also been observed in the developing rat intracerebellar nuclei (Gardette et al., 1985, their Figs. $3 B, D, E, 5 C, D, F)$. The develop- 


\section{0 day}
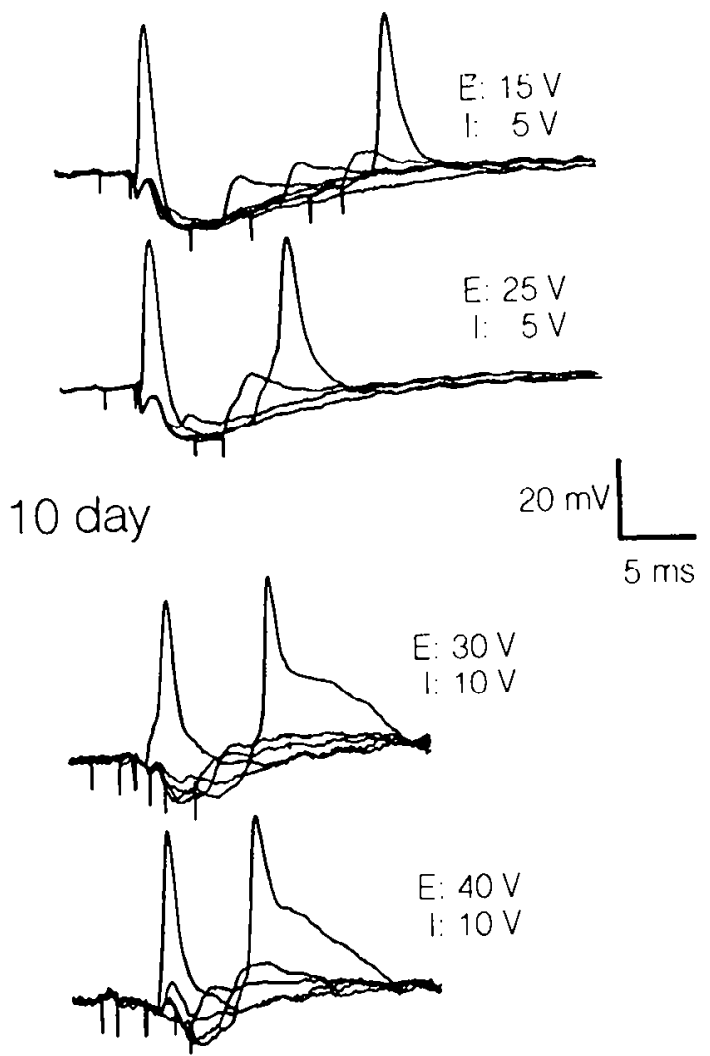

Figure 10. The duration of inhibition is level dependent at $10 \mathrm{~d}$ postnatal. An ipsilaterally evoked action potential was advanced through an MNTB-evoked IPSP in LSO neurons from two different $10 \mathrm{~d}$ animals. In both cases, when the ipsilateral stimulus level was increased, there was a concomitant decrease in the duration of time that the MNTBevoked IPSP was able to suppress the action potential. In the top set of mental significance of this response to inhibitory afferent stimulation is not yet clear. However, we have recently demonstrated that ongoing inhibitory activity does influence the maturation of LSO dendrites (Sanes and Chokshi, 1992; Sanes et al., 1992b) and the developmental refincment of single MNTB arbors within the LSO (Sanes and Takács, in press). I would speculate that since $\mathrm{Ca}^{2}+$ has been implicated in process outgrowth and retraction (Kater and Mills, 1991; Rehder and Kater, 1992), a rebound $\mathrm{Ca}^{2+}$-dependent depolarization resulting from glycinergic transmission would allow developing inhibitory afferents access to second messenger systems that are more commonly associated with excitatory pathways. The $\mathrm{Ca}^{2+}$ dependence of GABAergic transmission has now been documented in mature animals (Llano et al., 1991; Morishita and Sastry, 1991; Nishimoto et al., 1991). It is possible that such a synaptic mechanism could have implications for the maturation of inhibitory afferent specificity, as has been demonstrated for excitatory synaptic transmission (Constantine-Paton et al., 1990).

\section{The significance of central synaptic maturation on auditory processing}

The response of single LSO neurons to interaural intensity differences (IIDs) has been studied immediately following ear canal opening and in the adult gerbil (Sanes and Rubel, 1988). The resolution of single neurons is very poor in young animals, partly because the discharge rates are so low. In addition, some neurons appear to have a very irregular response as IID is altered. Immature functional characteristics are even more apparent in

traces, the suppression time decreased from 15 to $9 \mathrm{msec}$. In the bottom set of traces, the suppression time decreased from 6.8 to $5.5 \mathrm{msec}(E$, stimulus voltage to ipsilateral pathway; $I$, stimulus voltage to contralateral pathway).

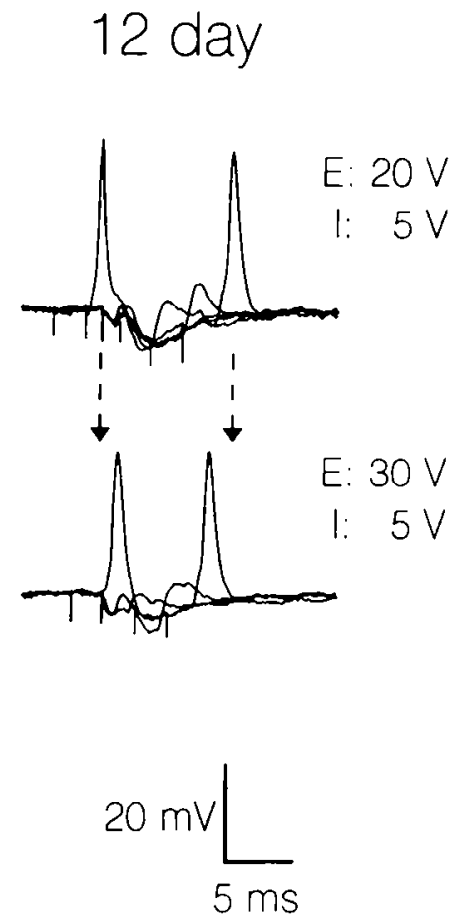

\section{4 day}
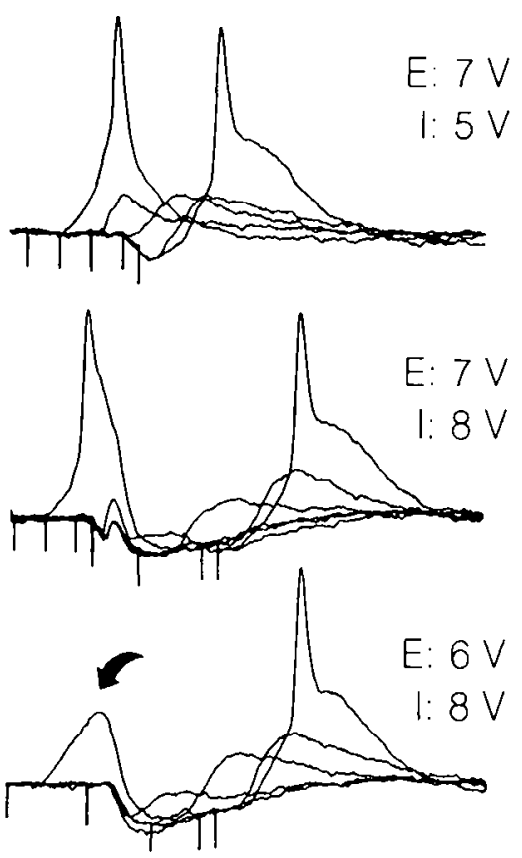

Figure 11. The duration of inhibition is level dependent at 12-14 d postnatal. An ipsilaterally evoked action potential was advance through an MNTB-evoked IPSP in $12 \mathrm{~d}$ (left) and $14 \mathrm{~d}$ (right) neurons. In the $12 \mathrm{~d}$ neuron (left), when the ipsilateral stimulus voltage was raised from 20 to $30 \mathrm{~V}$, the duration of suppression decreased from $9.1 \mathrm{msec}$ to $6.4 \mathrm{msec}$. The decreased suppression was apparent at both the onset and offset of the IPSP (dashed arrows). In the $14 \mathrm{~d}$ neuron, when the contralateral stimulus voltage was raised from 5 to $8 \mathrm{~V}$, the duration of suppression increased from $7.3 \mathrm{msec}$ to $15 \mathrm{msec}$. A subsequent decrease in the ipsilateral stimulus level from 7 to $6 \mathrm{~V}$ led to enhanced suppression at the leading edge of the IPSP (curved arrow) ( $E$, stimulus voltage to ipsilateral pathway; $I$, stimulus voltage to contralateral pathway). 
single neurons recorded from the kitten inferior colliculus (Moore and Irvine, 1981), where it is also found that irregular and variable changes in discharge rate occur as IID is altered. A recent study on the emergence of single-ncuron auditory receptive fields in the guinca pig demonstrates that the orderly progression of responses to auditory space is not apparent until postnatal day 32, even though hearing begins in utero (Withington-Wray et al., 1990). Before this age, individual neurons respond diffusely to stimuli located in the contralateral hemifield. Presumably, the integration of several monaural and binaural cues is required to attain adultlike spatial sensitivity, and the developmental process operates over an extended period of time.

The extended PSP durations and shallow rise times in LSO neurons (Table 1) would be cxpected to have a deleterious effect on time-critical binaural computations. Although the LSO is commonly associated with level difference detection, it may well play a role in time difference detection as well (Finlayson and Caspary, 1991), especially for high-frequency amplitude-modulated sounds (Henning, 1974; McFadden and Pasanen, 1976; Yost, 1976; Nuetzel and Hafter, 1981; Hafter et al., 1988). The temporal summation of PSPs, however, would be expected to have direct effect on level difference coding. For example, the ambiguity introduced by temporal summation and fatigue prevents the reliable occurrence of an action potential to identical stimuli (Fig. 5). In this regard, the variability of sound-cvoked discharge patterns in the kitten $\mathrm{CN}$ has recently been demonstrated (Fitzakerly et al., 1991).

The alteration of synaptic properties reported above demonstrates the contribution of central auditory maturation to binaural coding. Furthermore, the prominent durations and amplitudes of the synaptic potentials suggest that both excitatory and inhibitory transmissions may themselves have an influcnce on the developmental process.

\section{References}

Akagi H, Miledi R (1988) Heterogeneity of glycine receptors and their messenger RNAs in rat brain and spinal cord. Science 242:270-273.

Araki T, Terzuolo CA (1962) Membrane currents in spinal motoneurones associated with the action potential and synaptic activity. J Neurophysiol 25:772-789.

Bekoff A, Stein PSG, Hamburger V (1975) Coordinated motor output in the hindlimb of the 7 day chick embryo. Proc Natl Acad Sci USA 72:1245-1248.

Boudreau JC, Tsuchitani C (1970) Cat superior olive s-segment cell discharge to tonal stimulation. In: Contributions to sensory physiology, Vol 4 (Neff WD, ed), pp 143-213. New York: Academic.

Browner RH, Webster DB (1975) Projections of the trapezoid body and the superior olivary complex of the kangaroo rat (Dipodomys merriami). Brain Behav Evol 11:322-354.

Caird D, Klinke R (1983) Processing of binaural stimuli by cat superior olivary complex. J Comp Neurol 91:209-241.

Cant NB, Casseday JH (1986) Projections from the anteroventral cochlear nucleus to the lateral and medial superior olivary nuclei. J Comp Neurol 247:457-476.

Constantine-Paton M, Cline HT, Debski E (1990) Patterned activity, synaptic convergence, and the NMDA receptor in developing visual pathways. Annu Rev Neurosci 13:129-154.

Coombs JS, Eccles JC, Fatt $P$ (1955) The inhibitory suppression of reflex discharges from motoneurones. J Physiol (Lond) 130:396-413.

Curtis DR, Eccles JC (1959) The time course of excitatory and inhibitory synaptic actions. J Physiol (Lond) 145:529-546.

Eccles JC (1969) The inhibitory pathways of the central nervous system. Springfield, IL: Thomas.

Finck A, Schneck CD, Hartman AF (1972) Development of cochlear function in the neonate Mongolian gerbil (Meriones unguiculatus). J Comp Physiol Psychol 78:375-380.
Finlayson PG, Caspary DM (1991) Low-frequency neurons in the lateral superior olive exhibit phase-sensitive binaural inhibition. J Neurophysiol 65:598-605.

Fitzakerly JL, McGee J, Walsh EJ (1991) Variability in discharge rate of cochlear nucleus neurons during development. Soc Neurosci Abstr 17:304.

Fitzgerald M, Koltzenburg M (1986) The functional development of descending inhibitory pathways in the dorsolateral funiculus of the newborn rat spinal cord. Dev Brain Res 24:261-270.

Gardette R, Debono M, Dupont J-L, Crepel F (1985) Electrophysiological studies on the postnatal development of intracerebellar nuclei neurons in rat cerebellar slices maintained in vitro. I. Postsynaptic potentials. Dev Brain Res 19:47-55

Glendenning KK. Hutson KA, Nudo RJ, Masterton RB (1985) Acoustic chiasm. II. Anatomical basis of binaurality in lateral superior olive of cat. J Comp Neurol 232:261-285.

Hafter ER, Buell TN, Richards VM (1988) Onset-coding in lateralization: its form, site, and function. In: Auditory function: neurobiological bases of hearing (Edelman GM, Gall WE, Cowan WM, eds), pp 647-676. New York: Wiley.

Harnischfeger G, Neuweiler G, Schlegel P (1985) Interaural time and intensity coding in superior complex and inferior colliculus of the echo locating bat Molossus ater. J Neurophysiol 53:89-109.

Harris D, Dallos P (1984) Ontogenetic changes in frequency mapping in a mammalian cochlea. Science 225:741-743.

Henning GB (1974) Detectability of interaural delay in high-frequency complex waveforms. J Acoust Soc Am 55:84-90.

Hubel DH, Wiesel TN (1965) Binocular interaction in the striate cortex of kittens reared with artificial squint. J Neurophysiol 28:10411059 .

Hubel DH, Wiesel TN, LeVay S (1977) Plasticity of ocular dominance columns in the monkey striate cortex. Philos Trans R Soc Lond [Biol] 278:377-409.

Hyson RL, Rubel EW (1989) Transneuronal regulation of protein synthesis in the brain-stem auditory system of the chick requires synaptic activation. J Neurosci 9:2835-2845.

Jackson H, Parks TN (1982) Functional synapse elimination in the developing avian cochlear nucleus with simultaneous reduction in cochlear nerve axon branching. J Neurosci 2:1736-1743.

Jackson H, Hackett JT, Rubel EW (1982) Organization and development of hrain stem auditory nuclei in the chick: ontogeny of postsynaptic responses. J Comp Neurol 210:80-86.

Kater SB, Mills LR (1991) Regulation of growth cone behavior by calcium. J Neurosci 11:891-899.

Komatsu Y (1983) Development of cortical inhibition in kitten striate cortex investigated by a slice preparation. Dev Brain Res 8:136-139.

Komatsu Y, Iwakiri M (1991) Postnatal development of neuronal connections in cat visual cortex studied by intracellular recording in slice preparation. Brain Res 540:14-24.

Krnjevic K, Kandic M, Straughan DW (1964) Unit responses and inhibition in the developing cortex. J Physiol (Lond) 175:21-22.

Larsell O (1931) The effect of experimental excision of one eye on the development of the optic lobe and opticus layer in larvac of the treefrog. J Exp Zool 58:1-20.

Levi-Montalcini $R$ (1949) The development of the acoustico-vestibular centers in the chick embryo in the absence of the afferent roo fibers and of descending fiber tracts. J Comp Neurol 91:209-241.

Lippe W (1984) Rhythmic spontaneous activity in the developing avian auditory system. Soc Ncurosci Abstr 10:1159.

Llano I, Leresche N, Marty A (1991) Calcium entry increases the sensitivity of cerebellar Purkinje cells to applied GABA and decreases inhibitory synaptic currents. Neuron 6:565-574.

Llinás R, Yarom Y (1981) Properties and distribution of ionic conductances generating electroresponsiveness of mammalian inferior olivary cells in vitro. J Physiol (Lond) 315:569-584.

Luhmann HJ, Prince DA (1991) Postnatal maturation of GABAergic system in rat neocortex. J Neurophysiol 65:247-263.

Maximova EB (1971) Inhibition of the spinal reflex responses in the last period of embryogenesis. Neurofiziologie 3:68-74

McFadden D, Pasanen EG (1976) Lateralization at high frequencies based on interaural time differences. J Acoust Soc Am 59:634-639.

Moore DR, Irvine DRF (1981) Development of responses to acoustic interaural intensity differences in the cat inferior colliculus. Exp Brain Res 41:301-309.

Moore MJ, Caspary DM (1983) Strychnine blocks binaural inhibition in lateral superior olivary neurons. J Neurosci 3:237-247. 
Morest DK (1968) The collateral system of the medial nucleus of the trapezoid body of the cat, its neuronal architecture and relation to the olivo-cochlear bundle. Brain Res 9:288-311.

Morishita W, Sastry BR (1991) Chelation of postsynaptic $\mathrm{Ca}^{++}$facilitates long-term potentiation of hippocampal IPSPs. Neuroreport 2:533-536

Naka K-I (1964) Electrophysiology of the fetal spinal cord. II. Interaction among peripheral inputs and recurrent inhibition. J Gen Physiol 47:1023-1038.

Nishimoto I, Wagner JA, Schulman H, Gardner P (1991) Regulation of $\mathrm{Cl}^{-}$channels by multifunctional CaM kinase. Neuron 6:547-555.

Nuetzel JM, Hafter ER (1981) Lateralization of complex waveforms: spectral effects. J Acoust Soc Am 69:11112-1118.

Oppenheim RW, Reitzel J (1975) Ontogeny of bchavioral sensitivity to strychnine in the chick embryo: evidence for the early onset of CNS inhibition. Brain Behav Evol 11:130-159.

Persson HE (1973) Development of somatosensory cortical functions. Acta Physiol Scand [Suppl] 394:1-64.

Purpura DP, Shofer RJ, Scarff T (1965) Properties of synaptic activities and spike potentials of neurons in immature neocortex. J Neurophysiol 28:925-942.

Rasmussen GL (1946) The olivary peduncle and other fiber projections of the superior olivary complex. J Comp Neurol 84:141-219.

Rehder V, Kater SB (1992) Regulation of neuronal growth cone filapodia by intracellular calcium. J Neurosci 12:3175-3186.

Romand R, Granier M-R, Marty R (1971) Développement postnatal de l'activité provoquéc dans l'olive supérieure latérale chez le chat par la stimulation sorore. J Physiol (Paris) 66:303-315.

Ryan AF, Woolf NK (1988) Development of tonotopic representation in the mongolian gerbil: a 2-deoxyglucose study. Dev Brain Res 41: $61-70$.

Sanes DH (1984) A developmental analysis of neural activity in the mouse auditory system: its onset, the ontogeny of stimulus following and its role during the maturation of frequency tuning curves. PhD thesis, Princeton University.

Sanes DH (1990) An in vitro analysis of sound localization mechanisms in the gerbil lateral superior olive. J Neurosci 10:3494-3506.

Sanes DH, Chokshi P (1992) Glycinergic transmission influences the development of dendritic shape. Neuroreport 3:323-326.

Sanes DH, Rubel EW (1988) The ontogeny of inhibition and excitation in the gerbil lateral superior olive. J Neurosci 8:682-700.

Sanes DH, Siverls V (1991) The development and specificity of inhibitory axonal arborizations in the lateral superior olive. J Neurobiol $22: 837-854$

Sanes DH, Takács C (in press) Activity-dependent refinement in inhibitory arborizations. Eur $\mathrm{J}$. Ncurosci, in press.

Sanes DH, Wooten GF (1987) Development of glycine receptor distribution in the lateral superior olive of the gerbil. J Neurosci 7:38033811 .

Sanes DH, Geary WA, Wooten GF, Rubel EW (1987) Quantitative distribution of the glycine receptor in the auditory brain stem of the gerbil. J Neurosci 7:3793-3802.

Sanes DH, Merickel M, Rubel EW (1989) Evidence for an alteration of the tonotopic map in the gerbil cochlea during development. J Comp Neurol 279:436-444.

Sanes DH, Song J, Tyson J (1992a) Refinement of dendritic arbors along the tonotopic axis of the gerbil lateral superior olive. Dev Brain Res 67:47-55.

Sanes DH, Markowitz S, Bernstein J, Wardlow J (1992b) The influence of inhibitory afferents on the development of postsynaptic dendritic arbors. J Comp Neurol 321:637-644.

Schwartzkroin PA, Kunkel DD (1982) Electrophysiology and morphology of the developing hippocampus of fetal rabbits. J Neurosci $2: 448-462$.

Schwob JE, Haberly LB, Price JL (1984) The development of physiological responses of the piriform cortex in rats to stimulation of the lateral olfactory tract. J Comp Neurol 223:223-237.

Shat7. CJ, Kirkwood PA (1984) Prenatal development of functional connections in the sat's retinogeniculate pathway. J Neurosci 4:13781397.

Spangler KM, Warr WB, Henkel CK (1985) The projections of principal cells of the medial nucleus of the trapezoid body in the cat. $J$ Comp Neurol 238:249-262.

Spitzer NC (1991) A developmental handshake: neuronal control of ionic currents and their control of neuronal development. J Neurobiol 22:659-673.

Tolbert LP, Morest DK, Yurgelun-Todd DA (1982) The neuronal architecture of the anteroventral cochlear nucleus of the cat in the region of the cochlear nerve root: horseradish peroxidase labelling of identified cell types. Neuroscience 7:3031-3052.

Wilson DA, Leon M (1986) Early appearance of inhibition in the neonatal rat olfactory bulb. Dev Brain Res 26:289-292.

Withington-Wray DJ, Binns KE, Keating MJ (1990) The developmental emergence of a map of auditory space in the superior colliculus of the guinea pig. Dev Brain Res 51:225-236.

Woolf NK, Ryan AF (1984) The development of auditory function in the cochlea of the mongolian gerbil. Hearing Res 13:277-283.

Woolf NK, Ryan AF (1985) Ontogeny of neural discharge patterns in the ventral cochlear nucleus of the mongolian gerbil. Dev Brain Res 17:131-147.

Wu SH, Oertel D (1986) Maturation of synapses and electrical properties of cells in the cochlear nucleus. Hearing Res 30:99-110.

Yost WA (1976) Lateralization of repeated filtered transients. J Acoust Soc Am 60:178-181.

Zook JM, DiCaprio RA (1988) Intracellular labeling of afferents to the lateral supcrior olive in the bat, Eptesicus fuscus. Hearing Res 34: 141-148.

Zukin SR, Young AB, Snyder SH (1975) Development of the synaptic glycine receptor in chick embryo spinal cord. Brain Res 83:525-530. 